\title{
Research on the evaluation system of applied technology-oriented talents in application-oriented universities
}

\author{
Wang Jiaming ${ }^{1, a}$, Ding hao ${ }^{2, b}$ \\ ${ }^{1}$ School of Chinese Law and Economics Management, Shengli College China University of \\ Petroleum, Dongying Shandong, China \\ ${ }^{2}$ College of Economic and Management, China University of Petroleum (East China), Qingdao \\ Shandong, China

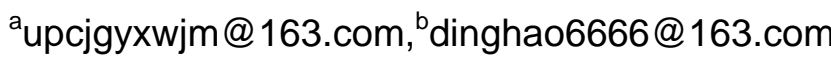 \\ ${ }^{\text {a } C o r r e s p o n d i n g ~ a u t h o r ~}$
}

Keywords: Applied technology-oriented university; Application-oriented talents; Factor analysis method

\begin{abstract}
Based on the demand situation for applied technology talents, this paper discusses the significance of constructing application-oriented talents' evaluation system for applied-Technical University, and the importance of training the applying technique-oriented talents to meet the social standard. Based on this, the paper focuses on discussing how to construct a set of evaluation terms which accord with the application of technical-oriented talents. We discussed the evaluation system from the aspects of comprehensiveness of evaluation subjects, mutual pushing of evaluation level, the identification of evaluation indexes and completeness of evaluation system. Based on the previous research and the combination of subjective and objective methods, this paper makes the evaluation standard of applied technology-based talents for the application of technology-based university and contributes to the evaluation of applied technical talents.
\end{abstract}

\section{Introduction}

The 2014 State Council decision on speeding up the development of modern vocational education pointed out: "To guide a number of general undergraduate colleges and universities to the application of technical types of higher education, focusing on undergraduate vocational education." On March 20, 2016 in the CPC Central Committee on deepening the reform of the institutional mechanism for the development of Human Resources, in order to cultivate the technical skilled talents who support China's manufacture and China's creation, we must deepen the system reform of technical skills and talents, innovate the evaluation mechanism of talents, and formulate the guidance of classifying and advancing talent evaluation mechanism. For the development of application-oriented undergraduate talents, it is helpful to explore and construct a scientific and effective system for the evaluation of talents in applied technology-based colleges, to promote the reform and development of educational teaching in the applied technical colleges, and to improve the quality of education and the integrity of classified education.

\section{Literature Review}

Researchers have carried out extensive and in-depth research on talent training and evaluation system. The research on the quality of talent training abroad arose in the the 1980s, the main research focuses on the standard of personnel training, the evaluation of talents training, and the establishment of quality assurance system of personnel training in colleges and universities. Edward Foldaway (1997) discussed the definition of the quality of talent training. He believed that the quality of talent training to achieve the desired level of education, and the quality of the measurement should be carried out in many ways. Quality of the standard is not the only measurement, the subject of the rating is educationally involved in the interests of the relevant people, including teachers, students, businesses and governments ${ }^{[1]}$. Tony Becher (1993) introduced 
the British Higher Education Quality Evaluation. The main body of the British Higher Education evaluation included all the research committees, and their evaluation basis and methods. The evaluation will also be based on results from academia and industry representatives to ensure the effectiveness of the evaluation ${ }^{[2]}$. In addition, John Brennan and Tara Shah (2000) respectively studied the theory and practice of quality assurance for talent training ${ }^{[3]}$.

Applied technology-based local college is based on the cultivation of applied technology talents. Researchers study mainly from six different aspects: policy support, transformation path, teaching reform, teacher construction, professional setting and personnel training. Such as Chao Wenyan et al. (2015) ${ }^{[4]}$ use literature research method, comparative study method, and multi-Factor comprehensive analysis method to make a comprehensive and in-depth analysis on the policy support of the construction of applied Technology University. Liu Xin et al. (2017) ${ }^{[5]}$ suggested the transformation for China's application of technology-based University. Based on Boyer's Multi-domain Academic concept, Wang Zhijun et al. (2015) ${ }^{[6]}$ explores the practical path of the development of application-oriented professors from the four aspects (academic, applied, academic and integrated academic research). Zhang Jin et al. (2016) ${ }^{[7]}$, Deng Hongda et al. (2016) ${ }^{[8]}$ and other scholars on the European and American applied Technology-based university professional setup experience. Shen Yang (2015) ${ }^{[9]}$ from the perspective of employers to evaluate the quality of personnel training in applied universities; Shi ying (2017) ${ }^{[10]}$ opposite to the modern service industry technology-based Management talent Training quality evaluation system for research; Li Hong (2016) ${ }^{[11]}$ based on CIPP model, this paper studies the evaluation Index system of application-oriented marketing talents.

To sum up, at present, there are few scholars at home and abroad to study the application of technology-based talent evaluation system, at the same time, in practice, there are many problems in the evaluation of applied technical personnel, so the article combined with the talent market for application-oriented talent demand situation, constructs a set of evaluation system of applied technology-based talents in application-oriented universities from the aspects of comprehensiveness of evaluation subjects, mutual push of evaluation level, the identification of evaluation indexes and the completeness of evaluation system, and formulates the evaluation standard of applied technology-based talents based on the methods of previous research and subjective and objective combination.

\section{Construction of evaluation index system of applied technical talents in applied technical universities}

Articles for the application technology of applied technology talents for the construction of evaluation system, focus on the practical and technical talents, so based on predecessors' research from innovation cultivation system, professional teachers' quality, students' quality and ability, students' knowledge level, evaluation of students' innovative ability and unit of choose and employ persons the six aspects on the application of the university of technology application technology talent training evaluation. The evaluation index system of applied technical talents in applied technical universities constructed based on this paper is shown in table 1. 
Table 1 Preliminary evaluation index system of Applied Technology Talents in Applied Technology Universities

\begin{tabular}{|c|c|c|c|}
\hline Target level & First level index & Second level index & Number \\
\hline \multirow{37}{*}{$\begin{array}{l}\text { Evaluation } \\
\text { system of } \\
\text { Applied } \\
\text { Technology } \\
\text { Talents in } \\
\text { Applied } \\
\text { Technology } \\
\text { Universities }\end{array}$} & & Training plan for Applied Talents & I1 \\
\hline & Innovative training system & Applied training funding & I2 \\
\hline & & Construction of applied talents training base & I3 \\
\hline & \multirow{7}{*}{$\begin{array}{l}\text { Quality of professional } \\
\text { teachers }\end{array}$} & Teachers' innovative spirit & I4 \\
\hline & & Teaching and scientific research achievements & I5 \\
\hline & & Teachers' professional quality & I6 \\
\hline & & Professional ethics level & I7 \\
\hline & & Age structure of Teachers & I8 \\
\hline & & Teacher education structure & I9 \\
\hline & & Faculty Title Structure & $\mathrm{I} 10$ \\
\hline & \multirow{5}{*}{$\begin{array}{l}\text { Quality and ability of } \\
\text { students }\end{array}$} & Psychological quality & I11 \\
\hline & & Humanistic quality & $\mathrm{I} 12$ \\
\hline & & physical quality & $\mathrm{I} 13$ \\
\hline & & Ideological quality & I14 \\
\hline & & Moral quality & I15 \\
\hline & \multirow{5}{*}{ Knowledge level of students } & Basic knowledge level & I16 \\
\hline & & Professional knowledge level & $\mathrm{I} 17$ \\
\hline & & Cross knowledge level & I18 \\
\hline & & Innovative knowledge level & I19 \\
\hline & & Entrepreneurial knowledge level & $\mathrm{I} 20$ \\
\hline & \multirow{8}{*}{ Creativity of students } & Innovation consciousness & $\mathrm{I} 21$ \\
\hline & & innovative thinking & I22 \\
\hline & & Innovative skills & I23 \\
\hline & & Social practice ability & $\mathrm{I} 24$ \\
\hline & & Practical innovation results & I25 \\
\hline & & Award for discipline competition & I26 \\
\hline & & Student research papers & I27 \\
\hline & & Extracurricular innovation activities & $\mathrm{I} 28$ \\
\hline & \multirow{9}{*}{ Employer evaluation } & Practical innovation ability of graduates & I29 \\
\hline & & Basic theory level of graduates & I30 \\
\hline & & Graduate performance & I31 \\
\hline & & Enterprise's satisfaction with professional knowledge training & I32 \\
\hline & & $\begin{array}{c}\text { Enterprise's satisfaction with the comprehensive ability of } \\
\text { training talents }\end{array}$ & I33 \\
\hline & & $\begin{array}{c}\begin{array}{c}\text { Enterprise's satisfaction with social adaptability of talents } \\
\text { training }\end{array}\end{array}$ & I34 \\
\hline & & Personnel training quality brand awareness & I35 \\
\hline & & Salary of graduates & I36 \\
\hline & & Career development of graduates & I37 \\
\hline
\end{tabular}

\section{Index system optimization}

The index system needs to describe the evaluation object succinctly and fully, and this preliminary index system has three defects: firstly, the number of evaluation indexes is too large, up to 37; secondly, related problems between evaluation indexes need to be further tested; thirdly, the discrimination of evaluation indexes needs to be analyzed. Therefore, it is necessary to identify the relevant and discriminant indexes, and test some indexes system with high correlation and poor discrimination, so as to further simplify and optimize the evaluation index system.

\subsection{Relevancy screening}

Correlation analysis is to study the consistency of the two indicators, that is, for the evaluation of the main contribution of the two is consistent or similar to resolve doubts on the correlation of the larger indicators to screen, optimize the index system. At present, linear correlation analysis, partial analysis and distance analysis are the most mature methods to measure correlation. In this paper, linear correlation analysis is used and expressed by correlation coefficient R. Linear correlation can be divided into positive correlation, negative correlation and wireless correlation. Positive correlation refers to the consistency of the two variables in the evaluation of the main contribution, the correlation coefficient is positive; negative correlation refers to the evaluation of the main contribution is not consistent, the correlation coefficient is negative; wireless correlation refers to the correlation coefficient is zero, the two variables for the evaluation of the main contribution is 
not related.

The calculation of $r$ can be achieved by Pearson correlation coefficient, Spearman and Kendall correlation coefficient. Pearson correlation coefficients are used to calculate the data of continuous variable with fixed distance, and Spearman and Kendall correlation coefficients are used to calculate the ranking of discrete data or quantitative variables when the distribution of data or value of variable is obviously non-normal or unknown.

For ordinal variables, rank correlation is used to describe coefficients and coefficients. In this paper, we use the concise formula derived from C.E.Spearman, a British statistician.

$$
R=1-\frac{6 \sum_{1}^{N} d_{i}{ }^{2}}{N\left(N^{2}-1\right)}
$$

Among them, the variable value difference, that is, $i=1,2, \ldots \mathrm{N}$ and $\mathrm{N}$ are the times. SPSS19.0 statistical software was used to analyze the evaluation index system and get the correlation coefficient matrix. In this paper, the critical value $r=0.65$ is set. The correlation coefficient of four pairs of evaluation indexes in the correlation matrix is greater than the critical value. We delete five evaluation indexes, $I 19, I 24, I 31, I 33, I 35$. As shown in table 2 , the remaining 32 evaluation indexes form the second evaluation index system.

\subsection{Filter by discrimination}

In the construction of the evaluation index system, the ability of the evaluation index to distinguish the evaluation object is also indispensable. The competitiveness index of regional cultural industry refers to the competitiveness to distinguish different regional cultures. It is assumed that two or more evaluation regions have little difference in a certain index, and at the same time show high or low scores or values, or cannot fully explain the evaluated object, then this index is poor in discrimination. On the contrary, there is a significant difference in the evaluated object on the same index, so it can be judged that this index has a strong discrimination in the evaluation competitiveness. In the current academic research, the difference coefficient is used to describe the discrimination of the evaluation index, and the difference coefficient is expressed by the relative amount of standard deviation relative to the average size, as shown in formula (2).

$$
C V=s / x
$$

Where, $x$ is the average value and $s$ is the standard deviation. The larger the coefficient of variation is, the stronger the discrimination of the index is, and the worse the discrimination is.

Based on the above theory, we analyze and calculate the variation coefficient of each index in the second round of evaluation index system. In combination with the actual situation, 4 indexes with relatively small coefficient of variation, including $I 4, I 7, I 12$ and $I 15$, were deleted, and 28 indexes were retained to form the final evaluation index system, as shown in table 2.

\subsection{Verification of reasonableness}

At this point, through the preliminary construction of the evaluation index system of cultural industry competitiveness, together with the screening of relevancy and discrimination, the current evaluation index system has been formed, so the rationality of this index system remains to be verified. At present, the evaluation of the rationality of the evaluation index system in the academic circle focuses on factor analysis, AHP, fuzzy comprehensive evaluation, TOPSIS, etc. In this paper, the rationality of the evaluation index system is verified by factor analysis based on the research of wang li-ke (2013) and the above factor analysis data. Factor analysis validation is a statistical analysis method of how to represent many variables through a few factors and ensure the minimum information loss and no significant correlation between factors. In this paper, it is the indicator system formed by whether the 28 indicators can fully represent the original 37 indicators.

In factor analysis, variance is used to represent the information content, based on which the index system is established to construct a reasonable criterion. Set $S$ as the covariance matrix of the indicator data, and $\operatorname{trS}$ as the trace of the covariance, that is, the sum of the variance of each indicator on the main diagonal of the covariance matrix. $S$ is the number of indexes after screening, 
$h$ is the number of indexes after selection, then the information contribution rate of the selected indexes to the selection indexes $I_{n}$ is:

$$
I_{n}=\frac{\operatorname{tr} S_{s}}{t r S_{h}}=99.2 \%
$$

That is, 76 percent (28/37) of the indicators selected from the audition indicators reflect 99.2 percent of the original information. Experience shows that this index system is reasonable.

\subsection{Determination of index weight}

The single objective weighting method cannot consider the actual significance of the index, and the weight calculation results will be greatly different from the actual importance of the index, while the single subjective weighting law will lead to too strong subjectivity and a large gap in expert empowerment. Therefore, it is necessary to select the combination weighting method combining subjective and objective to obtain a more reasonable index weight. This paper combines the subjective analytic hierarchy process and objective entropy method to give weight.

The combined weighting method combines the weighted results of multiple weighting methods to form the comprehensive weight, so as to avoid the fact that the single objective weighting method cannot consider the actual meaning of the index and the single subjective weighting method is too subjective to reflect the reality. The comprehensive weight calculation is shown in formula (4).

$$
W_{\text {Combination weight }}=\alpha W_{\text {subjective weight }}+(1-\alpha) W_{\text {objective weight }}
$$

The weight $a$ coefficients represent two kinds of weighting methods. The analytic hierarchy process and the entropy method belong to the subjective weighting method and the objective weighting method respectively. When calculating the combined weight, it is considered that the two weighting methods are equally important, with the weight of $0.5, a=0.5$. The weight results of combined weighting method are shown in table 2. 
Table 2 Final evaluation index system of Applied Technology Talents in Applied Technology Universities

\begin{tabular}{|c|c|c|c|c|c|c|c|}
\hline Target level & first level index & weight & second level index & number & $\begin{array}{c}\text { AHP } \\
\text { weight }\end{array}$ & $\begin{array}{l}\text { entropy } \\
\text { method } \\
\text { weight }\end{array}$ & $\begin{array}{c}\text { total } \\
\text { weight }\end{array}$ \\
\hline \multirow{28}{*}{$\begin{array}{l}\text { Evaluation } \\
\text { system of } \\
\text { Applied } \\
\text { Technology } \\
\text { Talents in } \\
\text { Applied } \\
\text { Technology } \\
\text { Universities }\end{array}$} & \multirow{3}{*}{$\begin{array}{l}\text { Innovative } \\
\text { training system }\end{array}$} & \multirow{3}{*}{0.15} & Training plan for Applied Talents & I1 & 0.3 & 0.28 & 0.044 \\
\hline & & & Applied training funding & I2 & 0.4 & 0.46 & 0.065 \\
\hline & & & Construction of applied talents training base & I3 & 0.3 & 0.26 & 0.042 \\
\hline & \multirow{5}{*}{$\begin{array}{l}\text { Quality of } \\
\text { professional } \\
\text { teachers }\end{array}$} & \multirow{5}{*}{0.1} & Teaching and scientific research achievements & I4 & 0.3 & 0.32 & 0.031 \\
\hline & & & Teachers' professional quality & I5 & 0.3 & 0.22 & 0.026 \\
\hline & & & Age structure of Teachers & I6 & 0.1 & 0.15 & 0.013 \\
\hline & & & Teacher education structure & I7 & 0.1 & 0.12 & 0.011 \\
\hline & & & Faculty Title Structure & I8 & 0.2 & 0.19 & 0.020 \\
\hline & \multirow{3}{*}{$\begin{array}{l}\text { Quality and } \\
\text { ability of } \\
\text { students }\end{array}$} & \multirow{3}{*}{0.1} & Psychological quality & I9 & 0.4 & 0.46 & 0.043 \\
\hline & & & physical quality & $\mathrm{I} 10$ & 0.3 & 0.31 & 0.031 \\
\hline & & & Ideological quality & I11 & 0.3 & 0.23 & 0.027 \\
\hline & \multirow{4}{*}{$\begin{array}{l}\text { Knowledge } \\
\text { level of } \\
\text { students } \\
\text { Creativity of } \\
\text { students }\end{array}$} & \multirow{4}{*}{0.2} & Basic knowledge level & I12 & 0.2 & 0.22 & 0.042 \\
\hline & & & Professional knowledge level & I13 & 0.3 & 0.28 & 0.058 \\
\hline & & & Cross knowledge level & I14 & 0.3 & 0.26 & 0.056 \\
\hline & & & Entrepreneurial knowledge level & I15 & 0.2 & 0.24 & 0.044 \\
\hline & \multirow{7}{*}{$\begin{array}{l}\text { Creativity of } \\
\text { students }\end{array}$} & \multirow{7}{*}{0.25} & Innovation consciousness & I16 & 0.2 & 0.21 & 0.051 \\
\hline & & & innovative thinking & I17 & 0.2 & 0.21 & 0.051 \\
\hline & & & Innovative skills & I18 & 0.2 & 0.21 & 0.051 \\
\hline & & & Practical innovation results & I19 & 0.1 & 0.08 & 0.023 \\
\hline & & & Award for discipline competition & $\mathrm{I} 20$ & 0.1 & 0.09 & 0.024 \\
\hline & & & Student research papers & $\mathrm{I} 21$ & 0.1 & 0.09 & 0.024 \\
\hline & & & Extracurricular innovation activities & $\mathrm{I} 22$ & 0.1 & 0.11 & 0.026 \\
\hline & \multirow{6}{*}{$\begin{array}{l}\text { Employer } \\
\text { evaluation }\end{array}$} & \multirow{6}{*}{0.2} & Practical innovation ability of graduates & $\mathrm{I} 23$ & 0.2 & 0.18 & 0.038 \\
\hline & & & Basic theory level of graduates & $\mathrm{I} 24$ & 0.1 & 0.11 & 0.021 \\
\hline & & & $\begin{array}{l}\text { Enterprise's satisfaction with professional knowledge } \\
\text { training }\end{array}$ & $\mathrm{I} 25$ & 0.2 & 0.19 & 0.039 \\
\hline & & & $\begin{array}{c}\text { Enterprise's satisfaction with social adaptability of talents } \\
\text { training }\end{array}$ & I26 & 0.2 & 0.19 & 0.039 \\
\hline & & & Salary of graduates & I27 & 0.1 & 0.12 & 0.022 \\
\hline & & & Career development of graduates & $\mathrm{I} 28$ & 0.2 & 0.21 & 0.041 \\
\hline
\end{tabular}

\subsection{Preliminary processing of data}

The data of the index system have obvious differences such as different dimensions, order of magnitude and positive and negative directions. This paper adopts the method of fuzzy membership function proposed by American scholar L.A. zaden. The forward index is quantified by using the half - liter fuzzy membership function. For the reverse index, the semi-reduced trapezoid fuzzy membership function is adopted for quantization. See formula (5) and (6) respectively:

$$
\begin{gathered}
\overline{R_{\mathrm{i}}}=\frac{R_{i}-R_{\min }}{R_{\max }-R_{\min }} \\
\overline{R_{\mathrm{i}}}=\frac{R_{\max }-R_{i}}{R_{\max }-R_{\min }}
\end{gathered}
$$

\subsection{Data acquisition and evaluation model selection}

Because the scientific and systematic evaluation method can carry on the quantitative analysis to the evaluation object, plays the guiding role for the scientific decision. Therefore, many famous experts and scholars at home and abroad have conducted a lot of research and exploration on it and formed a variety of views, including AHP, expert weight method, cluster analysis, grey system theory, factor analysis, fuzzy neural network analysis and so on.

It can be seen from table 2 that the evaluation index system composed of 28 indicators refers to the quantitative and qualitative ones. Therefore, it is a key step for data acquisition to evaluate applied technical talents in applied technical universities by using this evaluation index system. Quantitative data can be used by collecting and sorting out. However, it is difficult for us to judge 
qualitative data directly through a certain data. Therefore, this paper proposes to collect qualitative data by means of analytic hierarchy process and DELPHI expert opinion method. Before the measurement of the qualitative index, it was taken as a comprehensive index and assigned as the evaluation basis through questionnaire design and interview calculation. After obtaining complete qualitative and quantitative data, the membership function is used to standardize the data to eliminate the impact of too large data gap and long-term trend of qualitative data caused by different experts, and then the data is processed with the weight, and finally the evaluation subject is evaluated by selecting the systematic evaluation method.

\section{Summary}

This paper discusses the significance of constructing the evaluation system of applied technical talents for applied technical universities from the situation of the personnel market for applied technical talents, and discusses the objective inevitability of cultivating applied technical talents for the purpose of meeting social needs. The following conclusions are mainly drawn:

1. The key research of applied technology talents evaluation system, mainly from the evaluation subject, evaluation of comprehensive level of colliding, the correlation of evaluation index, the point and the integrity of the evaluation system to identify, build a set of six primary indexes and 28 secondary indicators of application technology college of applied technology talents evaluation system.

2. The evaluation index system constructed by this article shall pay attention to the acquisition of data (especially the acquisition of qualitative index data), and scientific processing shall be conducted before the data can be used.

3. At the beginning of the study, it aims to build a set of applied technical talents evaluation system that is in line with the application of technical universities. Until the construction of the evaluation system is completed, the selection of evaluation model and the acquisition of data in the later stage are still to be discussed, which also provides direction for the later research and provides reference for the research on personnel training in the application of technical universities.

\section{Acknowledgements}

This research was financially supported by the Following Foundation.

1. Social science planning research project of shandong province: Study on evaluation index system of cultural industry innovation capacity of shandong province (Grant NO.16CGLJ45);

2. Chunhui major project of shengli college of China university of petroleum: Study on efficiency measurement and development path of social science construction in shandong province (Grant NO.KY2018005);

3. Key project of art science of shandong province: A study on the development index system and empirical evaluation of cultural industry in shandong province based on correlative and discrimination (Grant NO.201806390);

4. Special project of social science planning research in shandong province: Research on the improvement path of government credibility from the perspective of socialized government (Grant NO.18CQXJ40).

\section{References}

[1] Xue jing. Research on big data model for quality evaluation of talent cultivation in universities [D]. Anhui university of technology,2017.

[2] Chang xiaoming. Analysis on the construction of quality evaluation system for higher vocational personnel training [J]. Chinese adult education,2014(14):98-100. 
[3] Cheng jianjun, wu xu. On the quality evaluation of talent cultivation from the perspective of harmonious campus development [J]. Heilongjiang higher education research,2009(01):137-140.

[4] Zhao Wenyan. Application technology policy support for the construction of university research [D]. Inner Mongolia normal university, 2015.

[5] Liu xin. University of applied technology development mode in developed countries to transformation in Chinese universities enlightenment [J]. Journal of jiangsu province economic and trade professional technology institute, 2017 (01) : 73-76.

[6] Wang. The practice of application technology university teacher development path - based owed and the concept of multi-domain academic [J]. Journal of higher engineering education research, 2015 (03) : 129-129.

[7] Zhang Jin, granular. The analysis and research of the European university of applied technology professional Settings, taking an example of German university of applied technology [J]. Journal of electronic test, 2016 (6) : 170-171.

[8] Deng Hong, zhao mei-yu. Application of metal material engineering technology university of China and the United States the major setting and course arrangement comparison [J]. Journal of chongqing institute of technology (social science edition), 2016 (02) : 118-120 + 118.

[9] Shen Yang. Study on employer evaluation of talent cultivation quality of applied technology university [D]. Harbin university of science and technology,2015.

[10] Li hong, gao liangliang. Study on the evaluation index system of school-enterprise cooperation in cultivating applied technical marketing talents based on CIPP model [J]. Oil education,2016(06):66-69.

[11] Shi ying. A preliminary study on the quality evaluation system for cultivating technical management talents for modern service industry [J]. Human resource management,2017(03):33-35. 